九州大学学術情報リポジトリ

Kyushu University Institutional Repository

\title{
GENETIC STRUCTURALISM IN BIOLOGY
}

Kitagawa, Toshio

The International Institute for Advanced Study of Social Information Science, Fujitsu Limited.

https://doi.org/10.5109/13391

出版情報: Bulletin of informatics and cybernetics. 23 (1/2), pp.1-7, 1988-03. Research Association of Statistical Sciences

バージョン :

権利関係 : 


\title{
GENETIC STRUCTURALISM IN BIOLOGY
}

\author{
By
}

\section{Tosio Kitagawa*}

\section{Introduction and Summary}

The reason why I have had keen interests with structuralism in biology is based upon an amalgamation of the ideas and/or concepts having been introduced and used in some of my own research areas: (a) biomathematical models including those of cell space and formal neural dynamics (1-1); (b) relativistic logics in statistics and informatics (1-2); (c) generalised relational ecosphere of knowledge information processing systems (1-3); (d) logics in informatics (1-4); (e) genetic epistemology (1-5). My concern with structuralism in biology came from (a) and (d), but I have to refer to what I may call genetic structuralism in view of (a) and (e). Since our genetic structuralism should have a deep connection with and also a profound implication on (c), it is necessary for genetic structuralism to have an intimate connection with structuralism in biology so as to establish a mutual cooperation with the two structuralisms. Our genetic structuralism in the present infanty stage does seem to give an impulse to our prospects concerning revolutions in logics, mathematics, statistics, and informatics.

The paper proposes a research methodology, which is tentatively called a genetic structuralism to biology. There are three components in organizing our genetic structuralism, each of which is illustrated in each of the following three Sections. Section 2 is concerned with a theoretical model regarding logics and mathematics, which our genetic structuralism requires and which are coined by the name of relativistic logics and generative mathematics respectively. Relativistic logics has its origin in statistics and informatics as model and structure building organ, and is in sharp distinction with the current classical formal logics. Generative mathematics represents our development methodology of mathematics to be required in our genetic structuralism, and is to be distinct with the current mathematics on the basis of either formalism of Hilbert or intuitionism of Brouwer. Section 3 is concerned with the notion of general relational ecosphere formed on the basis of local subspaces by which we want to settle a general feature of the world of the biological existences. Our generalised relational ecosphere is an abstract formulation which can be specified and materialised in detail according to each chosen specified area of biology. Section 4 discusses our prospect of the rôles and the functions of what we call computer biology. The name biocomputer is introduced here to specify these rôles and the functions of the computer to be required, whose whole realization and implementation are belonging to the future task for the present computer technology. The last Section 5 gives an integration of our discussions given in the three previous Sections. In fact we are now setting up the three

\footnotetext{
* The International Institute for Advanced Study of Social Information Science, Fujitsu Limited.
} 
coordinate axises formulation consisting of the theoretical model axis, the experimental and/or survey frame axis, and the biocomputer axis, each of which is generated by theory organ, description organ, and implementation organ respectively. The reason why we emphasise structuralism comes from the first and the second axises. Our emphasis is placed upon genesis, development, and evolution which are essential requirements for any division of biological science. In order to formulate this requirement, two considerations are set up through our formulations in the first and the third axises. It is noted that our genetic structuralism will be expected to play an essential rôle in promoting science and/or savoir revolution in the coming days. Further comments are given first regarding Asian or Japanese philosophy which is implicitly underlying the ideas of the present paper and secondly regarding the establishment of knowledge information processing systems (KIPS) in various fields of human activities (1-6)*.

\section{Relativistic Logics and Generative Mathematics as Theory Organ in Genetic Structuralism}

[1] Relativistic logies in concept formation In sharp contrast with formal logics, relativistic logics is concerned with the procedures how and under what conditions concepts in intension and sets in extension are formed in view of their basic requirements such as shown in the following instances:

(i) Formation process of establishing equivalence relation. (2-1)

(ii) Restrictive uses of transitivity law. $(2-2)^{*}$

(iii) Elaboration process of fuzzy logics. $(2-3)^{*}$

In principle, relativistic logics is based upon the following procedure:

$\left(1^{\circ}\right)$ Starting with an initial situation in which we have no precisely defined standards regarding either intension or extension.

$\left(2^{\circ}\right)$ Relying upon an accumulation of experiences by which we research gradual formation of tentative cluster and ecosphere as primitive forms of extension in logics. $(2-4)^{*}$

$\left(3^{\circ}\right)$ Application of internal checks within tentative cluster and among tentative clusters which lead to either rejection or tentative acceptance. $(2-5)^{*}$

$\left(4^{\circ}\right)$ Presenting a concept as a hypothesis to the set of clusters and/or ecospheres and appealing to a process of testing a sequence of null hypothesis. $(2-6)^{*}$

$\left(5^{\circ}\right)$ Abductive procedure leading to a new cluster formation and/or to a new hypothesis in the sequence of procedures $\left(2^{\circ}\right)-\left(4^{\circ}\right) \cdot(2-7)^{*}$

Relativistic logics can be compared with formal logics and statistical logics in the following sets of keyword sequences:

Formal logics: extension-standard-intension

Statistical logics: set-object-probabilization

Relativistic logics: cluster-relation-virtualization.

See Kitagawa (88).

[2] Generative mathematics in model formation Here we are deeply concerned with the realistic features of application of pure mathematics to model formation in various intellectual activities, and we want to propose to systematize them in the name 
of generative mathematics for which each of logicism (B. Russell), intuitionims ( $\mathrm{J}$. Brouwer), and formalism (D. Hilbert) is an important component, but is not sufficient in itself. In fact we appeal to the following procedure in some clear formulation which leads at least to a partial automatic procedure in its implementation:

$\left(1^{\circ}\right)$ A set of alternative axiom systems $\{\mathfrak{A} i \mid i=1,2, \cdots k\}$ is prescribed.

$\left(2^{\circ}\right)$ The set of $k$ independent conclusions $\{B i \mid i=1,2, \cdots k\}$ is deduced, each $B i$ from $\mathfrak{A} i$ respectively. $(i=1,2, \cdots k)$.

$\left(3^{\circ}\right)$ Comparion tests among the set $\{B i \mid i=1,2, \cdots k\}$ are applied either by mutual comparion within themselves or by comparison with already existing cognate standards.

$\left(4^{\circ}\right)$ Successive uses of null hypothetical test sequences are applied leading to amalgamation (pooling) and separation (including rejection).

$\left(5^{\circ}\right)$ In view of the consequences of $\left(4^{\circ}\right)$, abductive procedure is used to formulate a new set of axioms, which is, then, handled to the initial process mentioned in $\left(1^{\circ}\right)$.

As readily observed, there is a remarkable assimilation between the procedure in relativistics logics used in datalogy and generative model formation currently used in the choice of theoretical model. See Kitagawa (87a). (2-8)*

\section{Generalised Relational Ecosphere of Knowledge Information Processing Systems as Descriptions Model in Biology}

The reason why we adopt and how we formulate generalised relational ecosphere of knowledge information processing systems comes from the following five principles which we set up as a dogma in choosing our descpiption organ, which, we hope, is suited to either biology as a whole or any specific intelligible subsystm of biology. Here the notion of intelligible subsystm is due to A. Toyenbee. (3-1)*.

Principle 1. Each of three Gestalten, namely, biological machine, and semiotic ones, corresponds to nature, civilization and culture respectively. (3-2)

Principle 2. There is no biological phenomena without information, and conversely no information without biological phenomena. Here biological phenomena belong to nature, while information processing is implemented by biological existence in nature as well as by machine in civilization and understood by semiotics in culture.

Principle 3. Biological existences and phenomena can be and should be understood from the standpoint of genetic structuralism as knowledge information processing system (KIPS) in their generalised ecospheres of KIPS (GREKIPS). (3-3)

Principle 4. KIPS and GREKIPS are provided with the following set of theoretical frameworks as description organ:

( I) A set of local subspaces and global space formulated by means of paired categories with morphoids. (3-4).

(II) Each KIPS has twelve component expression:

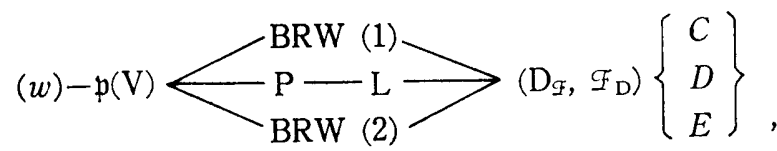

where each notion is undersood as follows: $\left(C_{1}\right)(w)$ : outerworld; $\left(C_{2}\right) \mathfrak{p}$ : subjective ex- 
istence; $\left(C_{2}\right) \mathrm{V}$ : view of $\mathfrak{p} ;\left(C_{4}\right) \mathrm{P}$ : information processor; $\left(C_{5}\right) \mathrm{L}$ : generalised artificial grammer; $\left(C_{6}\right) \mathrm{BRW}(1)$ : brainware of the first kind; $\left(C_{7}\right) \mathrm{BRW}(2)$ : brainware of the second kind; $\left(C_{8}\right) \mathrm{D}_{\mathscr{T}}$ : information material in flow; $\left(C_{9}\right) \mathscr{F}_{\mathrm{D}}$ : information flow scheme; $\left(C_{00}\right) C$ : Cognition function; $\left(C_{11}\right) D$ : Direction function; $\left(C_{12}\right) E$ : Evaluation function. (3-5)

(III) The whole process of knowledge information processing procedures can be described through the expression (II).

(IV) Informative logics associated with each KIPS is given through three coordinate system. (3-6)

Principle 5. There are various types of KIPS in which some of twelve components are lacking, and genesis and developments of each individual KIPS should be considered with reference to GREKIPS to which they belong. $(3-7)^{*}$

\section{Biocomputer as an Implementation Organ for Genetic Structuralism in Biology}

Let us start with the rôles and the functions of implementation organ for genetic structuralism approaches in general by referring to the following two items $\left(1^{\circ}\right)$ and $\left(2^{\circ}\right)$, and then let us mention the specific features of those particularly in biology in the latter ones $\left(3^{\circ}\right)$ and $\left(4^{\circ}\right)$.

$\left(1^{\circ}\right)$ The simultaneous uses of triple organs, namely, theory, description, and implementation ones, are essential in realizing and promoting genetic structuralism approaches, when implementation organ implies the feasibility of CASE (Computer Aided Simulation Experiment). (4-1)

$\left(2^{\circ}\right)$ The meaning of computer is flexible owing to the progress and the availability of computer technology and also due to a choice among various alternatives so as to suit to each specific research area. (4-2)

$\left(3^{\circ}\right)$ Biocomputer in the present context means an integrated system of distributed workstations chosen for research purpose of biology as a whole or of each specific division of biology, such as genetics, neuroscience, ecology, embryology and so on. A choice of biocomputer system is closely connected with theory and description organs. $(4-3)$

$\left(4^{\circ}\right)$ CASE by means of biocomputer sets implies game theory approach and possiblely dramatological one also. $(4-4)_{1},(4-4)_{2,3} *$

\section{Conclusion on Implication of Genetic Strcturalism}

It is noted that genetic structuralism approaches in biology is expected not only to bring some substantial contribution to biology in a systematic way, but also to give a basic impulse to uncover some of the basic problems now encountering in academic and practical communities. Here we shall be satisfied with mentioning the following four topics:

$\left(1^{\circ}\right)$ An implication to a formation of image of science revolution and/or savoir revolution in the present time is explained in one of our papers. $(5-1)^{*}$ 
$\left(2^{\circ}\right)$ Man and machine viewed from cultural backgrounds are discussed through essentially the same theoretical framework as the present one due to genetic structuralism. (5-2), (5-2)*

$\left(3^{\circ}\right)$ Our uses of relativistic logics in $\S 2$ and those of GREKIPS in $\S 3$ can be shown to have a certain connection with the Japanese philosophy due to Nishida and the language activity process due to Tokiyeda according to Prof. Y. Nakamura. (5-3)*

$\left(4^{\circ}\right)$ The present formulation of genetic structuralism in biology has a close connection with that of artificial intellignece approach, which is shown in our recent paper. (5-4)*

\section{References}

For the convenience of systematic references, the author prepare a copy of the titles of the papers in Scientific Contributions of Prof. Tosio Kitagawa. Reference notions are given in the text by the notion $(i-k)$ where $i$ denotes Section $i$, while $k$ denotes the order of citation in the Section. These notations $(i-k)$ as shown in Reference A are mentioned in the copy of the title of the papers, while $(i-\mathrm{k}) *$ implies that the reference can not be found there, because they refer either to the contribution by other scholars or my recent paper which is not included in the Collection, and a description in Reference $\mathrm{B}$ is given to each of $(i-k)^{*}$.

\section{Referenee $(\mathbf{A})$}

(a) Each one set of Scientific Contributions of Prof. Tosio Kitagawa, A.I A.IX, 1985, can be found in the following institutions.

(1) Research Institute of Fundamental Information Science, Facuity of Scinece, Kyushu University, Fukuoka, Japan.

(2) Institute of Statistical Mathematics, Tokyo, Japan.

(3) Statistical Laboratory, Princeton University, Princeton, New Jersey, U.S.A.

(4) Statistical Laboratory, Iowa State University, Ames, Iowa, U.S.A.

(5) Statistical Laboratory, University of California, Berkeley, California, U.S.A.

(6) International Institute for Advanced Study of Social Information Science, Fujitsu Limited, Ohta-ku, Tokyo 144, Japan.

A. I. Functional equations (15 papers)

A. II. Stochastic analysis (19 papers)

A.II. Statistical inference process (14 papers)

A.IV. Statistical control and design processes (15 papers)

A.V. Cell space approaches in biomathematics (12 papers)

A.VI. Formal neural dynamics in biomathematics (10 papers)

A.VII. Logical foundations of information sicnece and scientific information systems (19 papers)

A. III. Generalised relational ecospheres of knowledge information processing systems (16 papers)

A. IX. Miscellaneous contributions (13 papers)

(b) In connection with these nine volumes, the complete references are given as follows:

A. II. 2-4 (2-1); A. V.1-12 (1-1) $;$; A. VI.1-10 (1-1) 2 ; A.VII.1.1-1.6 (1-2), (1-4), (1-5),

(3-6); A. VII. 1.1-1.2 (4-1), (4-4) 1 ; A. 怔. 2.1-2.4 (1-3), (3-3), (3-4), (3-5), (4-2), (4-3);

A. XX. $1.8(3-2),(5-2)$

(c) With reference to the original papers, the following abbreviated list containing a set of representative papers is given as follows:

A.II.2.3 Automatically Controlled Sequence of Statistical Procedures in Data Analysis, Mem. Fac. Sci., Kyushu Univ., Ser. A, 17 (1963), 106-129.

A. III.2.4 The Relativistic Logic of Mutual Specfication in Statistics, Mem. Fac. Sci., 
Kyushu Univ., Ser. A, 17 (1963), 76-105.

A. III.2.5 Automatically Controlled Sequence of Statistical Procedures, Bernoulii (1723), Bayes (1763), Laplace (1813) Anniversary Volume, Proc. of Intern. Res. Seminar Stat. Lab. Univ. of Calif., Berkeley 1963, Springer-Verlag, Berlin, Heiderberg, New York (1965), 146-178.

A. V.10 Cell Space Approaches in Biomathematics, Mathematical Biosciences, 19 (1974), 27-71; Mathematical Bioscience, 17 (1973), 1-45.

A. II.7 Neural Equation Approaches to Recognition Processes on the Basis of Reverberation and Virtual Dynamics, Intern. Symp. on Math. Topics in Biology, Kyoto Univ., Sept. 11-12 (1978), 121-130.

A. IT.8 Formal Neural Dynamics, Fifth European Meeting on Cybernetics and Systems Research, IX, Cybernetics in Biology and Medicine; Cybernetics in Cognition and Learning Health Care Systems (ed. by R. Trappl, L. Ricciardi and H. Pask), (1982), $161-172$.

A. VI. 1.1 Three Coordinate Systems for Information Science Approaches, Research Institute of Fundamental Information Science, Kyushu Univ, Research Report, 8 (1971), 123 ; Information Sciences, 5 (1973), 157-169.

A.II.1.5 Mathematical Approaches in Theoretical Cybernetics and Informatics, Research Institute of Fundamental Information Science, Kyshu Univ., Research Report, 73 (1976), 1-23; 8th Intern. Congress on Cybernetics, Namur (1976), 268-283.

A.IIII.2.2 An Informatical Formnlation of Generalized Relational Ecosphere on the Basis of Paired Categories, Proc. Intern. Conference on Cybernetics and Society, TokyoKyoto, Nov. 3-7 (1978), 1, 322-327.

A. III.2.3 Generalized Artificial Grammars and Their Implications to Knowledge Engineering Approaches, Intern. Inst. Advanced Study of Soc. Information Sci., Research Report, 6 (1979), 1-29.

A.III.2.4 Mathematical Formulation of Generalized Relational Ecosphere of Local TimeSpaces, The 8th International Congress of Mathematical Biology, September (1981); Intern. Inst. Advanced Study of Soc. Information Sci., Research Report, 28 (1982), $1-27$.

A.LX.1.8 Man and Machine Viewed from Different Cultural Backgrounds, Intern. Inst. Advanced Study of Soc. Information Sci., Research Report, 53 (1985), 1-29.

\section{Reference B}

Kitagawa, T. (87): Several features of logical functions in knowledge information processing systems (in Japanese), The Second Symposium on Informatics, Science Council of Japan $(1-4)_{2}{ }^{*},(5-1)^{*},(5-4)^{*}$

Kitagawa, T. (86): Systems of binary term relations (in Japanese), Japanese Math. Soc., 1986 Autumn Consolidated Branch Division Meeting, Branch Division of Math. Statist., Preliminary Proc. $(2-2)^{*}$

Mahalanobis, P.C. (57): The foundation of statistics, Sankhya, 18, 183-194. (2-3) ${ }_{1}^{*}$

Haldane, J.R.S. (57): The SYADVADA system of prediction, Sankhya, 18, 195-210. $(2-3)_{2}{ }^{*}$

KITAGAWA, T. $(84 \alpha)$ : Statistical inference process (in Japanese), Information Sci. Series, A.5.5, Kyoritsu Shuppan, $(2-4)^{*},(2-5)^{*},(2-6)^{*}$

KITAGAWA, T. (84): Science revolution and methodological proposals in creative dimensions (in Japanese), Journal of Japan Creative Society, No. 2 Patterns of Creation, Kyoritsu Shuppan, 14-26. $(2-7)^{*},(5-1)^{*},(5-2)^{*}$

Kitagawa, T. $(87 \alpha)$ : Statistical information (in Japanese), I, II, Information Sci. Series, A.5.6A.5.7, Kyoritsu Shuppan Co., $(2-8) *,(5-3) *$

Kitagawa, T. (88): Relativistic logics and generative mathematics, (in Japaneses), Kagaku Kisoron Kenkyu, 69, Japan Association for Philosophy of Science 18-3, 61-68. (2-8)*.

Toyenbee, A. (34-61): A study of history, I-XII. (3-1)* 
KITAGAWA, T. (81): Some theory of generalised relational informational ecosphere (in Japanese), Japanese Research Report of Intern. Inst. Soc. Inform. Sci., 1, 1-42. (3-7) ${ }_{1}{ }^{*}$

Kitagawa, T. (83): An informatical approach to knowledge information processing systems (in Japanese), Japanese Research Report of Intern. Inst. Soc. Inform. Sci. 10, 1-55. (3-7) ${ }_{2}{ }^{*}$

Matsuo, K., Adachi, N. and Hosogi, S. (85): Evolution of strategic species in game world (in Japanese), The 11th System Symposium, The Society of Instrument and Control Engineers, Tokyo, 189-194. (4-4) ${ }_{2}^{*}$

Matsuo, K., Adachi, N. and Hosogi, S. (86): Social function of strategic species in game world (in Japanese), Consolidated Symp. of the 15th SICE Symp. on Control Theory and Control Engineers, Tokyo, 431-436. (1-6)*, $(4-4)_{3}{ }^{*}$.

Received September 30, 1987

The present paper was presented to the International Workshop on the Structuration in Biology held in Osaka, December 10th, 1986. 